\title{
ПОСТГОМИЦИДНЫЕ САМОУБИЙСТВА
}

\author{
А.В. Голенков \\ ФГБОУ ВО „Чувашский государственный университет им. И.Н. УАьянова», г. Чебоксары, Россия
}

Контактная информация:

Голенков Андрей Васимьевич - доктор медицинских наук, профессор (SPIN-код: 7936-1466; ORCID iD: 0000-0002-3799-0736). Место работы и должность: заведующий кафедрой психиатрии, медицинской психологии и неврологии ФГБОУ ВО «Чувашский государственный университет им. И.Н. УАьянова». Адрес: Россия, г. Чебоксары, ум. Пирогова, 6. Телефон: (905) 197-35-25, эмектронный адрес: golenkovav@inbox.ru

Самоубийство, совершённое после убийства - брутальная форма агрессивного поведения, которое редко наблюдается в повседневной жизни. На русском языке кратким и всеохватывающим является термин «постгомицидные самоубийства» (ПГСУ). В настоящем обзоре литературы ставилась цель рассмотреть основные результаты зарубежных исследований, посвящённых ПГСУ. Критерии квалификации ПГСУ колебались в широких временных пределах (часы и месяцы), не лишено оснований и предложение учитывать причинную связь между убийством и последующим самоубийством. Супружеские (партнерские) ПГСУ являются самыми распространёнными (40-70\% всех случаев), далее следуют детские (2,9-36\%), семейные (2-31,9\%) и внесемейные (2,9-40\%) ПГСУ. Распространённость ПГСУ в разных странах мира составляет от 0,4 до 8,9 случаев на 1 млн жителей. В Чувашии (регион России) случаи ПГСУ регистрируются от 1 до 6 случаев (в среднем $4,2 \pm 2,0$ случая в год) или от 0,8 до 4,84 (в среднем - 3,32) на 1 млн жителей. В литературе среди мотивов совершения ПГСУ обсуждаются: патологическая ревность (amorous jealousy), стрессы, “mercy killing” или altruistic; зачастую (в 25-50\%) выявить мотивы не удаётся. Важной причиной ПГСУ являются психические расстройства (ПР), доля которых составляет от 3 до 100\%. Отчетливо лидируют депрессивные состояния (от 8,6 до $87 \%$ ), много коморбидных состояний, ПР, обусловленных приёмом психоактивных веществ и различных форм суицидального поведения (мысли, попытки, самоповреждения) - в анамнезе от 2,6 до 51\%. ПГСУ значительно чаще совершают мужчины (75-91,4\% случаев). Жертвами, напротив, чаще становятся женщины и дети (50-83\%). Возраст убийц значительно превышает возраст жертв. Орудием убийств и самоубийств в большинстве стран является огнестрельное оружие. Допускается изучение ПГСУ в средствах массовой информации. Профилактика ПГСУ представляет весьма трудную задачу в связи с тем, что преступники и жертвы ПГСУ отличаются от обычных убийц и суицидентов. Указанные аспекты убеждают в исследовании ПГСУ в каждой стране (регионе) мира, чтобы определить свои специфические факторы совершения ПГСУ и разрабатывать меры его профилактики.

Ключевые слова: постгомицидные самоубийства (самоубийства, совершённые после убийства), психические расстройства, эпидемиология, факторы, профилактика

Самоубийство, совершённое после убийства - брутальная форма агрессивного поведения, которое редко $(0,01 \%$ в структуре всех смертей Англии и Уэльса) наблюдается в повседневной жизни, но производит шокирующее воздействие на общество [1]. В зарубежной научной литературе встречается довольно много различных исследований этого противоправного деяния [2-7 и др.], в отечественной ему уделено весьма скромное место $[8,9]$. Так, в руководстве по судебной психиатрии оно описывается в главе, посвящённой посмертной судебно-психиатрической экспертизе в уголовном процессе, под названием «расширенное самоубийство». На фоне депрессивного состояния (с тоской, тревогой, страхами, апатией, бредовыми идеями самообвинения и самоуничижения) у такого человека возникает решение покончить не только с собой, но и со своими близкими людьми, избавляя их от «кажущихся мучений» и искупая «мнимую вину» [10]. Од- нако в реальной жизни встречается много других вариантов и мотивов самоубийств, совершённых после убийств [3-6]. В связи с этим, на наш взгляд, более удачным и всеохватывающим является термин «постгомицидные самоубийства» (убийство - син. гомицид). В отечественной научной психиатрической литературе и учебниках для студентов медицинских и юридических ВУЗов встречаются такие расстройства как гомицидомания и гомицидофобия, поэтому постгомицидные самоубийства (ПГСУ) нам представляются вполне уместным термином, отражающим сущность совершённого деяния [8].

В своём предыдущем исследовании, посвящённом судебно - психиатрическим аспектам убийств, выполненном на репрезентативной выборке (766 психически больных убийц) за период с 1981 по 2010 гг. нам не встретились ПГСУ [11]. Можно предполагать, что эти случаи редко направляются на экспертизу в 
регионах России $[8,9]$. Между тем юристы в своих публикациях также затрагивают вопросы ПГСУ, что свидетельствует о междисциплинарном характере поднятой проблемы и её определённой актуальности [12].

В настоящем обзоре литературы ставилась цель рассмотреть основные результаты зарубежных исследований, посвящённых ПГСУ.

Критерии квалификации ПГСУ.

Является важным вопросом, который до конца не решён, поскольку временно̀й фактор совершения самоубийства после убийства существенно колеблется от 24 часов [6, 13-15], трёх дней $[1,16]$, одной $[4,17-20]$ или двух [21] недель, трёх месяцев $[2,22]$ до решения (осуждения) суда [23] или в течение всей последующей жизни убийцы [цит. по 5].

Одни исследователи считают очень важным обстоятельством акт самоубийства после убийства в течение нескольких (трёх) часов, максимум - одних суток $[21,24]$. Классическим критерием ПГСУ всё же считается совершение самоубийства после убийства в течение одной недели [4, 17-20]. Как показали наблюдения, $85-86,3 \%$ самоубийств после убийства совершаются агрессором в течение 24 часов $[16,25]$. Однако возможны колебания как в одну, так и другую стороны. Так, только $42 \%$ преступников совершили самоубийство в день убийства, 75\% - в течение трех дней, оставшиеся - до вынесения приговора суда [23]. По другим сведениям, 92,4\% ушли из жизни в течение 24 часов после совершённого убийства, через день - ещё $4,2 \%$, через два дня $-2,1 \%$, и через три дня $-1,3 \%$. В 17 случаях ПГСУ преступники совершили самоубийства в интервале от семи дней до 10 месяцев (в среднем через 78 дней, медиана -60 ), поэтому были исключены из анализа. Учёт этих случаев, по мнению авторов, чреват ошибками, превышающих пределы допускаемой погрешности в регистрации ПГСУ [1].

Существуют предложения, прежде всего, учитывать причинную связь между убийством и последующим самоубийством, а на время не обращать пристального внимания (может составлять и несколько месяцев) [22]. Некоторые авторы в нескольких своих исследованиях использовали разные временные критерии - от 24 часов до 1 недели $[5,6,16,23]$. Более того, бывают случаи, когда преступник ещё до смерти жертвы совершает самоубийство (3 случая из 147 [1]), а иногда (4-10\% в странах Европы) после агрессивного нападения человек остаётся живым, и это квалифицируется как попытка убийства с самоубийством. Впрочем, и у преступника акт самоубийства может оказаться только попыткой уйти из жизни (такие случаи парасуицида составляют от 25 до 37\%). ПГСУ не учитываются и исключаются из исследования, если убийство совершенно в группе (убийца точно не известен), когда связь между убийцей и жертвой окончательно не установлена [14]. К другим вариантам относят случаи, когда преступник был убит при задержании, его смерть наступила не в результате самоубийства [23]. Одним словом, включаются в исследование только «несомненные» и «правдоподобные» случаи самоубийств, совершённых после убийства [26]. Указанные обстоятельства существенно влияют на точность сбора статистических показателей ПГСУ [6].

Классификация ПГСУ. В настоящее время в большинстве исследований ПГСУ используется классификация P. Marzuk и соавт., построенная на связи между агрессором (убийцей) и его жертвой [19]. Выделяют четыре основных типа ПГСУ: супружеские (партнерские), детские, семейные и внесемейные [2, 5, 17]. Супружеские ПГСУ могут включать убийства по причине ревности широкой модальности, включая «синдром Отелло» (morbid jealousy; бред ревности), обусловленные другими межличностными конфликтами с разводом, прекращением отношений и одиночеством, которыми недовольна одна из сторон, что сопровождается раздражением, депрессией и агрессией $[27,28]$. Этот вариант в бо̀льшей степени характерен для сравнительно молодых людей в возрасте до 55 лет [29]. Для более старшего поколения (после 55 лет) причиной ПГСУ может явиться тяжелая болезнь (плохое здоровье, немощная старость, чаще у жертвы) и депрессивные состояния (чаще у преступника). Убийство чаще всего совершается мужчиной из милосердия (“mercy killing”) - прекращения мучений жертвы, после чего агрессор заканчивает жизнь самоубийством [I7, 23, 27]. Иногда такие ПГСУ основываются на «пакте о самоубийстве» (suicide pact) - договоренности между двумя и более людьми о совместном уходе из жизни, в котором участвует и виновник совершённого преступления [2].

ПГСУ с убийством ребёнка (детей) больше подходит под определение «расширенного самоубийства». Мать (реже отец), часто в состоянии депрессии (психического расстройства) решает, что больше никто не будет заботиться о ребёнке после совершения её (им) самоубийства, поэтому принимает решение убить перед этим своего ребёнка (детей) $[6,29]$. 
Другим нередко встречающимся вариантом такого ПГСУ является «альтруистическое убийство (altruistic homicide-suicide)» [I7]. Мать считает, что ребёнку (детям) угрожает какая-то опасность («злой дух, дьявольская сила», «мафия» и др.), сопровождающаяся страшными и длительными пытками, издевательствами с мученической смертью, поэтому убийство рассматривается её как гуманный поступок («меньшее из зол»), облегчающий уход из жизни ребёнка без страданий. Часто в этих случаях убийцы страдали выраженными ПР, сопровождающиеся бредом и галлюцинациями $[2,5]$.

C учётом возраста убитых детей среди ПГСУ выделяют неонациды (neonaticide; менее 24 часов после рождения), инфантициды (infanticide; от 1 дня до 1 года), педициды (pedicide; от 1 года до 16 лет), но чаще всего используется обобщённое название детоубийство (filicide) [2, 17].

Семейные ПГСУ включают убийство разных членов семьи и родственников. Здесь можно упомянуть так называемые убийства (самоубийства) по доверенности (homicide, suicide by proxy). Данное преступление чаще всего совершает мужчина (муж, отец семьи), который пессимистично рассматривает настоящее и будущее своей семьи, ощущает неспособность защитить её от многочисленных страданий, неудач, горя и катастроф. Основой таких поступков и суждений часто являются различные депрессивные состояния $[3,5,7]$.

В литературе описаны мужчины - так называемые «ликвидаторы семьи», которые убивают всех присутствующих - детей, находящихся на момент преступления дома (своих и чужих), супругу и даже домашних животных [2].
Семейных ПСГУ, включая ПГСУ детей, стало больше с 90-х годов прошлого столетия, и тенденция сохраняется до настоящего времени в Бельгии [29] и других странах Европы [6].

Внесемейные ПГСУ затрагивают чрезвычайно разнообразные группы индивидов от друзей, соседей, сотрудников по работе, знакомых до совершенно незнакомых и чужих людей. Это чаще всего случайные убийства, совершённые в результате конфликта на высоте раздражения, злобы и ярости $[2,5]$. В ряде случаев виновники убивают своих недругов (заклятых врагов), например, работодателя, который уволил с работы и др. [17]. Самоубийство является уходом от сурового наказания, мотивированное страхом обнаружения, разоблачения и ответственности. Среди внесемейных ПГСУ встречаются так называемые массовые убийства $[2,5]$, совершённые «школьными / колледжскими / университетскими стрелками». Здесь часто используется несколько единиц автоматического огнестрельного оружия, которые направлены на обидчиков убийцы. В основе месть за издевательства, третирование и различные прилюдные унижения (буллинг) со стороны окружающих (учителей и одноклассников). Иногда преступник хочет прославиться (войти в историю), поэтому стремится убить как можно больше людей, либо делает это по псевдорелигиозным (борьба с неверными), либо каким-то другим сверхценным идеям (отпор «феминизму»), совершая, в том числе, террористические акты $[2,5]$.

Лица, совершившие внесемейные ПГСУ, чаще имели проблемы с употреблением психоактивных веществ (ПАВ) и более молодой возраст (10-19 лет) по сравнению с другими типами ПГСУ [14].

Распределение разных видов ПГСУ по данным литературы

Таблица 1

\begin{tabular}{|c|c|c|c|c|c|c|c|c|c|c|c|}
\hline Вид ПГСУ & $\begin{array}{l}\Xi \\
\Xi \\
\text { 声 } \\
0 \\
0 \\
0\end{array}$ & 莺 & 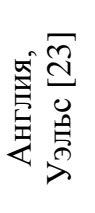 & 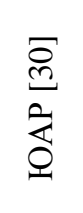 & $\begin{array}{l}\stackrel{\varpi}{\Xi} \\
\Xi \\
\Xi\end{array}$ & 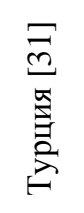 & 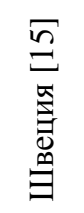 & $\begin{array}{l}\stackrel{n}{\Xi} \\
\underset{\Xi}{\Xi}\end{array}$ & 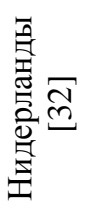 & 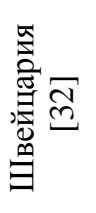 & $\begin{array}{l}\frac{\sqrt{2}}{\Xi} \\
\Xi \\
\Xi\end{array}$ \\
\hline $\begin{array}{l}\text { Супружеские, } \\
\text { партнерские }\end{array}$ & 46,4 & 43,0 & 65,0 & 62,8 & 58,0 & 40,0 & 53,6 & 56,6 & 60,0 & 69,0 & 70,0 \\
\hline Детские & 36,0 & 14,0 & 19,0 & 20,0 & 13,7 & 10,0 & 5,0 & 2,9 & 27,0 & 16,0 & 11,0 \\
\hline Семейные & 5,1 & 12,0 & 7,0 & 14,3 & 6,2 & 10,0 & 31,9 & 30,4 & 3,0 & 2,0 & 7,0 \\
\hline Внесемейные & 12,5 & 10,0 & 2,0 & 2,9 & 12,4 & 40,0 & 8,7 & 10,1 & 13,0 & 13,0 & 9,0 \\
\hline Другие & - & 6,0 & 7,0 & - & - & - & - & - & - & - & - \\
\hline Неизвестно & - & 15,0 & - & - & 10,0 & - & 0,8 & - & 7,0 & - & 3,0 \\
\hline
\end{tabular}


Как видно из табл. 1, супружеские убийства являются самыми распространёнными (40$70 \%$ всех ПГСУ), далее следуют детские (2,9$36 \%)$, семейные $(2-31,9 \%)$ и внесемейные $(2,9$ $40 \%)$ ПГСУ [13, 15, 17, 23, 24, 30-32]. В ряде случаев не удаётся квалифицировать ПГСУ изза отсутствия сведений о взаимосвязи преступника и его жертвы [14].

Редкая встречаемость внесемейных ПГСУ может служить критерием исключения их из анализа. Семейные («домашние») ПГСУ в Европе чаще всего регистрировались в Финляндии, Германии и Швейцарии, а реже всего - в Польше и Испании, промежуточное положение занимали Нидерланды, Англия и Уэльс. В их структуре $65 \%$ составили ПГСУ «интимных партнеров» (включая супругов, сожителей), детей $-15 \%$, родителей (супругов) и детей $9 \%$, ПГСУ с участием других членов семьи $11 \%$. Две и более жертвы наблюдались в $17 \%$ таких случаев (чаще всего в Финляндии и Нидерландах, а реже - 9\% - в Испании) [6].

Бывают случаи, когда жертв несколько и они относятся к разным группам ПГСУ. В этих случаях их квалифицируют как прочие (другие) ПГСУ [14]. Например, в исследовании В. Barraclough, E.C. Harris [1] таких ПГСУ было $7 \%$ (4\% - супружеские и семейные, $3 \%$ - семейные и внесемейные).

Распространенность ПГСУ. ПГСУ составляет в структуре убийств от 3 до $60 \%$ [15, $18,21,32]$. Такой разброс обусловлен различным пониманием (квалификацией) преступления, что может зависеть от культурных особенностей и страны проживания. В США ежегодно совершается 1000-1500 случаев ПГСУ или 0,2-0,3 на 100 тысяч населения [19], в Швейцарии - примерно три случая на 1 млн жителей (0,3 на 100 тысяч) [25]. M. Large с coавт. [4] в систематическом обзоре 64 эпидемиологических исследований обнаружили ПГСУ от 0,012 на 100 тыс. жителей в Шотландии в середине XX века до 1,33 - в Гренландии в 70-х годах прошлого столетия. Данные о распространении ПГСУ в странах мира представлены в табл. $2[1,5,9,13,14,17,20,23,24,31$, 32].

В Бельгии за 75 лет (1935-2010) наблюдения ПГСУ стало существенно больше, начиная с 90-х годов, а с 1935 по 1940 гг. они вообще не регистрировались [29]. В Нидерландах в 19922006 гг. (15 лет) уровень ПГСУ колебался от 0,07 до 0,02 на 100 тыс. населения, или в среднем 9 случаев в год [18]. В Англии и Уэльсе распространённость ПГСУ в 1996-2005 гг. составила 0,5 на 1 млн жителей, в 2006-2008 - 0,4 $[16,23]$. В ЮАР наблюдение ПГСУ в течение двух лет выявили различия в $16 \%$. В Чувашии (регион России) случаи ПГСУ колебались от 1 до 6 (в среднем $-4,2 \pm 2,0$ случая в год) [9].

Сравнение ПГСУ в трёх развитых странах показало, что наибольшие показатели регистрировались в США $(0,22$ на 100 тыс. жителей) против 0,09 (Швейцария) и 0,05 (Нидерланды). При этом самый высокий уровень самоубийств наблюдался в Швейцарии $(19,35)$, а уровень убийств - в США $(5,06)$ [32]. В США выявляется связь между ПГСУ и уровнем убийств. В других странах мира такая закономерность не прослеживается. В них определяется корреляция между ПГСУ и уровнем самоубийств [4].

Таблица 2

Распространенность ПГСУ в странах мира по данным литературы

\begin{tabular}{|c|c|c|c|}
\hline Авторы & Годы исследований & Страна (регион) & $\begin{array}{c}\text { Частота ПГСУ на } \\
1 \text { млн жителей } \\
\end{array}$ \\
\hline Barraclough B., Harris E.C., 2002 [1] & $1988-2002$ & Англия, Уэльс & 0,6 \\
\hline Carlach C., Grabosky P.N., 2004 [24] & 1989-1996 & Австралия & 2,2 \\
\hline Chan C.Y. с соавт., 2004 [17] & $1989-1998$ & Китай (Гонконг) & 0,9 \\
\hline Hata c соавт., 2001* & 1986-1995 & Япония (Тояма, Саппоро) & $0,6-1,5$ \\
\hline Panczak R. с соавт., 2013 [25] & $1991-2001$ & Швейцария & $2,95-3,01$ \\
\hline Liem M. с соавт., 2011 [32] & 1992-2006 & $\begin{array}{c}\text { Голландия } \\
\text { Швейцария } \\
\text { США } \\
\end{array}$ & $\begin{array}{l}0,5(0,4-0,6) \\
0,9(0,7-1,2) \\
2,2(2,0-2,5)\end{array}$ \\
\hline Flynn S. с соавт., 2009 [23] & 1996-2005 & Англия, Уэльс & 0,5 \\
\hline Roberts K. с соавт., 2010 [20] & $2000-2001$ & ЮAP & 8,9 \\
\hline Dogan K. с соавт., 2010 [31] & $2000-2007$ & Турция (Конья) & 0,64 \\
\hline Regoeczi W.C. с соавт., 2016 [15] & $2001-2010$ & $\begin{array}{c}\text { Швеция } \\
\text { США (1округ штата Огайо) }\end{array}$ & $\begin{array}{l}0,7 \\
2,0\end{array}$ \\
\hline Bossarte R.M. с соавт., 2006 [13] & $2003-2004$ & США & $2,30-2,38$ \\
\hline Moscowitz c coaвт., 2006* & 2006 & Новая Зеландия & 0,8 \\
\hline Голенков А.В., 2018 [9] & $2010-2016$ & Россия (Чувашия) & $3,33(0,8-4,84)$ \\
\hline
\end{tabular}

Примечание: *цит. по Liem M. с соавт., 2010 [5] 
Описанные закономерности ставят под сомнения эпидемиологические «законы» J. Coid o схожей распространённости ПГСУ в разных странах мира и малой вариабельности (неизменяемости) их во времени [33].

ПГСУ чаще всего совершается в пятницу, так как это последний рабочий день недели с максимумом накопленных стрессов и усталости, «выплескиванием» эмоциональных проблем на близких и окружающих [22]. Однако W. Regoeczi с соавт. отметили 25\% ПГСУ в выходные дни, в то время как в литературе в порядке убывания фигурировали: понедельник, вторник, пятница, суббота и четверг, воскресенье (в среду ПГСУ не было совсем) [15]. При этом какой-либо сезонной закономерности в совершении ПГСУ выявить не удалось $[1,5,7$, $18]$.

Причины ПГСУ. В литературе обсуждается довольно широкий спектр мотивов для совершения ПГСУ, причём были попытки сделать их одним из критериев классификации [3, $4,6]$. Однако существенные социально - психологические и культурные различия в разных странах мира пока оставляют это вопрос открытым [2, 5]. В Бельгии за 75 лет (1935-2010), согласно классификации P. Marzuk c соавт. [19], ПГСУ распределились следующим образом: из-за патологической ревности (amorous jealousy) $-56 \%$, стрессов $-27 \%$, "mercy killing" или altruistic - $15 \%$; не удалось выявить мотивы у 28 человек (25\%). ПГСУ по причине сострадания и альтруизма пришлось объединить из-за трудностей дифференцировки двух видов [29]. Также зачастую относят к одной группе причин ревность и расставание партнеров (развод, прекращение отношений и отдельное проживание) [17], называя их конфликтными отношениями между людьми [14], проблемами взаимоотношений [30].

Во многих исследованиях авторы сталкиваются с невозможностью использовать эту классификацию на практике, поэтому описание ПГСУ носят произвольный и обобщённый характер. К тому же важной причиной ПГСУ являются психические расстройства (ПР), которые вносят диссонанс в интерпретацию и понимание истинных мотивов данного деликта. К примеру, в уже приведённой выборке ПГСУ из Бельгии [29] депрессивные расстройства были квалифицированы у 59\% преступников (у 14\% в сочетании с соматическими болезнями), алкогольное опьянение - у $33 \%$, но эти дополнительные факторы никак не увязывались с типологией ПГСУ. В штате Огайо (США) существенным фактором в совершении
ПГСУ, показатели которых стабильны в течение 26 лет наблюдений (1991-2016), называют ревность и употребление ПАВ [34].

Проблемы здоровья звучали чаще при ПГСУ у пожилых людей: 34\% жертв, 30\% преступников и $36 \%$ обоих участников деликта имели серьёзную болезнь $(7,5 \%$ жертв - деменцию). Домашнее насилие прослеживалось в $24 \%$ случаев. Развод, расставание, разлука у партнеров выявлялась только в 13\%. Если мотивы для самоубийств у преступников-убийц старше 50 лет выявлялась в 74\% случаев, то у более молодых лиц их доля была значительно ниже [35].

Психические расстройства при ПГСУ. Частота психических расстройств (ПР) у убийц, совершивших самоубийства, колеблется от 3 до 100\%, чаще у пожилых преступников (в среднем 68\% - в трех исследованиях; $60 \%$ - аффективные расстройства) [7].

Около 39\% преступников имели депрессивные состояния, описанные в 20 исследованиях; $20 \%$ - ПР и расстройства поведения, обусловленные приёмом ПАВ (в 10), 17\% - различные психозы (в трёх исследованиях) [7].

Депрессивные расстройства у убийц в различных исследованиях были отмечены от 8,6 до $87 \%$. Описывался широкий спектр состояний различных по выраженности и длительности: большая и биполярная депрессия, дистимия. Тяжелая депрессия с психотическими проявлениями встречалась в трех работах у 75$87 \%$ преступников. Принимали антидепрессанты 12-15\%, лечились по поводу ПР - 21,6-33\%, стационарно в психиатрической больнице $25 \%$ (одно исследование) [7].

Шизофренией страдало 2-10\% убийц, другими психозами без уточнения диагноза - 2$75 \%$. Из бредовых отмечались идеи ревности («синдром Отелло»), «эротомания». Значительное число авторов предполагало высокую распространённость расстройств личности, однако их удалось подтвердить у $10(23,1 \%)$. Много было коморбидных состояний, ПР, обусловленных приёмом ПАВ [30]. В Италии признаки стрессовых расстройств выявлялись у $33 \%$ лиц, совершивших ПГСУ [22].

Различные формы суицидального поведения (мысли, попытки, самоповреждения) в анамнезе имели от 2,6 до 51\% лиц, совершивших ПГСУ [7]. В Англии и Уэльсе среди преступников депрессивные расстройства в структуре ПР выявлялись у 53\% (ситуационная депрессия была у 12\%), 1/3 получала психотропные препараты в момент ПГСУ, чаще всего антидепрессанты. $25 \%$ из них совершили от 1 
до 4 суицидальных попыток, 1/3 - обсуждали свои психологические проблемы (стресс, вызванный расставанием с любимым человеком, включая развод; проблемы с детьми, финансовые, изменения социального статуса; ухудшения здоровья; суицид у друзей и членов семьи) со своим семейным врачом в течение последнего года перед ПГСУ, $1 / 4$ - в течение месяца [16].

Значительно меныше ПР наблюдалось в исследованиях, основанных на газетных репортажах (9,6-33\%), в которых редко упоминались ПР, максимум - у $1 / 3$ убийц. Чаще всего описывались депрессивные состояния (от 20 до $75 \%$ ) непсихотического уровня, но с идеями (сверхценными) ревности [36].

Проблемы с алкоголем имели от 6 до 52\% убийц, с другими ПАВ - 5,6-18\%, алкогольную зависимость - 6,1-29\% [7]. В Австралии лица, совершившие ПГСУ, достоверно реже, чем обычные суициденты и убийцы имели проблемы с алкоголем, каннабисом и амфетаминами, опиаты употребляли примерно одинаковое число лиц (5\% против 7,1\% среди суицидентов и 4,1\% среди убийц) [26]. В межнациональных сравнениях преступники и жертвы реже (преступники - 21-50\%; жертвы - 12-50\%) употребляли ПАВ при ПГСУ по сравнению с обычными убийствами и самоубийствами и, как правило, в небольшом количестве (лёгкая степень опьянения; алкоголь в крови $-0,10$ "intoxication levels") [цит. по 15].

В Бельгии у 33\% убийц был обнаружен алкоголь в крови в диапазоне от 0,07 до 2,80 г/л (в среднем - 1,22), у жертв - в 13\% случаев, соответственно - 0,04-0,97 $(0,47)$ [29]. В Австралии алкогольное опьянение определялось у 20\% лиц, совершивших ПГСУ (средняя концентрация алкоголя в крови - 0,188 мг/100 мл) [26]. Наркотические вещества выявлялись у $20 \%$ преступников в США и у $3 \%$ - в Швеции [15].

Описанный разброс в показателях обусловлен нечёткостью методологии сбора материала. При оценке ПР - особенностью случаев ПГСУ, включённых в исследование (убийств детей, сексуальных партнеров, совершённых только пожилыми людьми), психиатрической грамотностью медработников и врачей общей (семейной) практики, а в ряде случаев и самих авторов исследований.

Пол, возраст и ПГСУ. Как видно из табл. 3, ПГСУ значительно чаще совершают мужчины (75-91,4\% случаев) $[16,17,20,23,24$, $28,37]$. Исключением является Япония, где равное число ПГСУ у мужчин и женщин [38]. Жертвами чаще становятся женщины (50-83\%). Возраст убийц значительно превышает возраст жертв, так как среди последних в 25-45\% оказываются дети в возрасте от 0 до 16 лет.

Таблица 3

Половозрастные особенности агрессоров и жертв ПГСУ в странах мира

\begin{tabular}{|c|c|c|c|c|c|c|c|c|c|c|}
\hline Показатель & $\begin{array}{l}\Xi \\
\Xi \\
E \\
0 \\
\vdots \\
0 \\
0\end{array}$ & 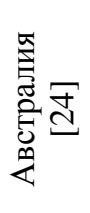 & 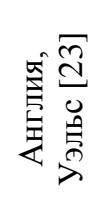 & 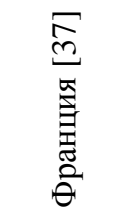 & 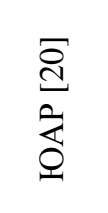 & $\begin{array}{l}\underset{\infty}{\mathbb{U}} \\
\underset{\Xi}{\Xi}\end{array}$ & 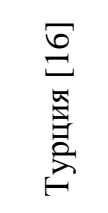 & 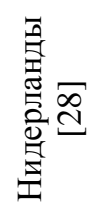 & 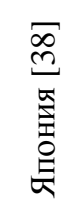 & 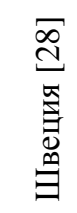 \\
\hline \multicolumn{11}{|c|}{ Преступники } \\
\hline Мужчины, \% & 75,0 & 91,4 & 86,0 & 85,0 & 91,4 & 92,0 & 90,0 & 90,0 & 49,4 & 92,0 \\
\hline Женщины, \% & 25,0 & 8,6 & 14,0 & 15,0 & 8,6 & 8,0 & 10,0 & 10,0 & 50,6 & 8,0 \\
\hline $\begin{array}{l}\text { Средний возраст } \\
\text { (диапазон), годы }\end{array}$ & 41,9 & 39,6 & $\begin{array}{l}44 \mathrm{M}^{*} \\
35 \text { ж}^{*}\end{array}$ & $\begin{array}{c}51 \mathrm{M}^{*} \\
40,5 \mathrm{~K}^{*}\end{array}$ & $\begin{array}{c}38,6 \\
24-73 \\
\end{array}$ & 45,6 & $\begin{array}{c}32,0 \\
21-48 \\
\end{array}$ & 40,9 & 51,6 & 49,1 \\
\hline \multicolumn{11}{|c|}{ Жертвы } \\
\hline Мужчины, \% & 36,5 & 26,4 & 23,0 & 40,0 & 20,9 & 25,0 & 4 сл. & 32,0 & 39,0 & 34,0 \\
\hline Женщины, \% & 63,5 & 73,6 & 77,0 & 60,0 & 79,1 & 75,0 & 8 сл. & 68,0 & 50,0 & 66,0 \\
\hline Дети, \% & 35,7 & НД* & 19,0 & 45,0 & 20,0 & 12,0 & 3 сл. & 36,0 & 25,0 & 15,0 \\
\hline $\begin{array}{l}\text { Средний возраст } \\
\text { (диапазон), годы }\end{array}$ & 32,3 & 33,2 & $\begin{array}{l}36,0 \\
0-89 \\
\end{array}$ & НД* & $\begin{array}{c}26,0 \\
0,5-72 \\
\end{array}$ & 39,2 & $\begin{array}{c}26,0 \\
0,2-50\end{array}$ & 28,2 & 35,4 & 39,2 \\
\hline $\begin{array}{l}\text { Доля многочислен- } \\
\text { ных жертв }\end{array}$ & 28,6 & 20,8 & 19,0 & 28,6 & 14,3 & 12,0 & 20,0 & 20,0 & НД* & 18,0 \\
\hline
\end{tabular}

Примечание: *НД - нет данных; сл. - случаи; м - мужчины, ж - женщины. 
Однако ПГСУ с убийством детей чаще (51,5-75,0\% случаев) совершали женщины с помощью удушения своих жертв и других «более гуманных» по сравнению с огнестрельным оружием методов убийства $[14,32]$; иногда перед убийством женщины давали детям снотворные препараты $[6,29]$. Таких ПГСУ особенно много было в Нидерландах (18\%) по сравнению со Швейцарией и США (8-9\%) [32]. Эти женщины (детоубийцы) чаще лечились у психиатров, принимали антидепрессанты, имели проблемы не только с психическим, но и соматическим здоровьем [14].

Примерно в $80 \%$ случаев убийцы находились в возрастной группе от 25 до 64 лет, буквально единичные случаи регистрировались у несовершеннолетних преступников. Примерно по $10 \%$ приходилось на возрастные группы 18 24 года и 65 лет и старше (табл. 4) [6, 31, 32]. При внесемейных ПГСУ доля преступников в возрасте 20-49 лет достигала $76,2 \%$, а при семейных - 61,4\%. 37,1\% супружеских ПГСУ совершали мужчины в возрасте 50 лет и старше [14].

Может наблюдаться два пика совершения убийств мужчинами - в 45 и 75 лет, возраст младше 20 лет у них практически не встречается [25]. Они имели низкий уровень образования $(76,6 \%),{ }^{2} / 3$ - безработные [17], принадлежали преимущественно к низкому социальному классу [25]. В Швейцарии наивысший риск совершения ПГСУ рассчитан для иностранцев (мигрантов), не имеющих постоянного гражданства, мужчин без религиозной принадлежности, граждан, проживающих в перенаселенных жилищах, что ассоциируется с психологическим стрессом и низким уровнем социальной поддержки. Но отсутствуют связи с уровнем образования участников ПГСУ, их занятостью, национальностью, числом детей, языком региона и степенью урбанизации [25].

В ряде исследований предпринимались попытки сравнить ПГСУ у лиц старше 55 лет и младше 55 лет. Группы различались только по частоте ПГСУ: 4-9 случаев на 1 млн жителей у тех, кому > 55 лет против 3-7 - у тех, кому менее 55 лет [39]. Анализ показал, что ПГСУ в возрасте $>55$ лет не регистрировались в Бельгии в 1935-1955 гг., а младше 55 лет совершались примерно с одинаковой частотой на протяжении 75 лет (1935-2010). В старшей возрастной группе преступники совершали ПГСУ чаще по мотивам милосердия (43\%), среди жертв преобладали женщины (32\%); из орудий убийства они использовали огнестрельное оружие (42\%) либо прибегали к избиению
(32\%), самоубийство совершали через повешение $(53 \%)$ или с помощью огнестрельного оружия (37\%). Преступники до 55 лет расстреливали свои жертвы (71,4\% случаев) из-за ревности $(80 \%)$, самоубийства также совершали с помощью огнестрельного орудия $(71 \%)$. Увеличение ПГСУ в этой стране с 90 -х годов авторы объясняют постарением населения (увеличением возраста преступников и жертв), ростом депрессивных состояний и учащением финансовых кризисов [29].

Таблица 4

Возрастные группы преступников и жертв ПГСУ в некоторых странах мира

\begin{tabular}{|c|c|c|c|c|c|}
\hline $\begin{array}{l}\text { Возраст, } \\
\text { годы }\end{array}$ & 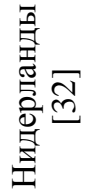 & 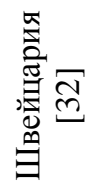 & 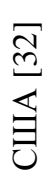 & 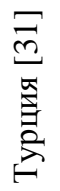 & 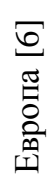 \\
\hline
\end{tabular}

Преступники

\begin{tabular}{l|c|c|c|c|c}
\hline$<17$ & 1,0 & - & - & - & - \\
\hline $18-24$ & 8,0 & 6,0 & 8,0 & 20,0 & 5,0 \\
\hline $25-39$ & 46,0 & 25,0 & 32,0 & 60,0 & 30,0 \\
\hline $40-64$ & 41,0 & 44,0 & 47,0 & 20,0 & 48,0 \\
\hline$>65$ & 4,0 & 17,0 & 13,0 & - & 17,0 \\
\hline Нет данных & - & 8,0 & - & - & - \\
\hline
\end{tabular}

Жертвы

\begin{tabular}{l|c|c|c|c|c}
\hline$<17$ & 36,0 & 15,0 & 12,0 & 33,3 & 25,0 \\
\hline $18-24$ & 7,0 & 8,0 & 12,0 & 16,7 & 8,0 \\
\hline $25-39$ & 32,0 & 27,0 & 29,0 & 33,3 & 24,0 \\
\hline $40-64$ & 19,0 & 38,0 & 34,0 & 16,7 & 29,0 \\
\hline$>65$ & 6,0 & 12,0 & 13,0 & - & 15,0 \\
\hline Нет данных & - & - & - & - & 7,0 \\
\hline
\end{tabular}

Жертвы в 55-65\% это люди в возрасте 2564 года, несовершеннолетние составляли около $25 \%$ и примерно по $10 \%$ - лица в возрасте 18 24 года и 65 лет и старше.

Орудия преступления (способы убийств и самоубийств). Орудием убийств в большинстве стран является огнестрельное оружие (табл. 5) [6, 17, 29-31, 36, 40]. Наивысшие показатели регистрируются у населения США, далее следует Швейцария, Франция, ЮАР, Австралия, Канада, Нидерланды, Англия и Уэльс. Во Франции это боевое (нарезное) оружие, короткоствольные (обрезные) и охотничьи («дробовики») ружья [37]. В Швейцарии в $64 \%$ это гражданское огнестрельное оружие, в $18 \%$ - служебное (боевое ручное), в $12 \%$ нелегально приобретённое [32]. 
Орудия / способы убийств и самоубийств ПГСУ в некоторых странах мира

\begin{tabular}{c|c|c|c|c|c|c|c}
\hline Орудия / Способ & $\begin{array}{c}\text { Гонконг } \\
{[17]}\end{array}$ & $\begin{array}{c}\text { ЮАР } \\
{[30]}\end{array}$ & $\begin{array}{c}\text { Бельгия } \\
{[29]}\end{array}$ & $\begin{array}{c}\text { Турция } \\
{[31]}\end{array}$ & $\begin{array}{c}\text { Нидерлан- } \\
\text { ды [40] }\end{array}$ & $\begin{array}{c}\text { Европа } \\
{[6]}\end{array}$ & $\begin{array}{c}\text { Англия, } \\
\text { Уэльс [36] }\end{array}$ \\
\hline
\end{tabular}

Убийства

\begin{tabular}{l|c|c|c|c|c|c|c}
\hline Огнестрельное & - & 87,1 & 54,2 & 66,7 & 38,6 & 48,0 & 10,0 \\
\hline Холодное & 24,3 & 4,3 & 9,4 & 8,3 & 27,9 & 17,0 & 37,0 \\
\hline Тупое & 10,8 & - & 12,5 & - & 4,3 & 7,0 & - \\
\hline Удушение & 25,7 & - & 17,7 & 16,7 & 15,7 & 10,0 & 30,0 \\
\hline Отравление & 14,9 & - & - & 8,3 & 4,3 & - & - \\
\hline Падение с высоты & 13,5 & - & - & - & 2,1 & - & - \\
\hline Транспортное средство & - & - & 3,1 & - & - & - & - \\
\hline Поджог & - & 4,3 & - & - & - & - & - \\
\hline Другое / Неизвестно & 10,8 & 4,3 & 3,1 & - & 7,1 & 18,0 & 23,0 \\
\hline
\end{tabular}

Самоубийства

\begin{tabular}{l|c|c|c|c|c|c|c}
\hline Огнестрельное & - & 76,1 & 55,0 & 70,0 & 34,9 & 45,0 & 8,0 \\
\hline Холодное & 5,0 & 4,8 & 2,5 & - & - & 9,0 & 17,0 \\
\hline Тупое & - & - & & - & 6,6 & - & - \\
\hline Повешение & 13,3 & 9,5 & 35,0 & - & 8,5 & 16,0 & 33,0 \\
\hline Отравление & 21,7 & - & 1,2 & - & 2,8 & 3,0 & 8,0 \\
\hline Падение с высоты & 48,3 & - & - & - & 4,7 & 9,0 & - \\
\hline Утопление & - & - & - & - & 1,0 & - & 8,0 \\
\hline Поджог & - & 4,8 & - & - & 2,8 & - & - \\
\hline Транспорт средство & - & - & 2,5 & - & 7,6 & - & - \\
\hline Другое / Неизвестно & 11,7 & 4,8 & 3,8 & 30,0 & 31,1 & 18,0 & 26,0 \\
\hline
\end{tabular}

Огнестрельное оружие самый «надёжный» метод суицида (смерть в странах Европы регистрируется в 90\% и выше), «успешность» других способов ухода из жизни колеблется от 39 до 63\% [6]. В 4-8\% случаев в странах Европы жертвы оставались живы после нападения, что квалифицировалось как попытка убийства, хотя агрессоры после этого совершали самоубийства. Эти случаи иногда также включаются в статистику ПГСУ для научного анализа и увеличения выборки наблюдения, которая зачастую слишком мала.

В табл. 5 из стран резко выделяется Китай (Гонконг), где огнестрельное оружие не используется [17]. Не самым частым методом оно является для Англии и Уэльса [36]. Аналогичные тенденции можно наблюдать и в регионах России $[8,9]$. Однако, что касается нападений больных на врачей и медицинских работников в нашей стране, закончившихся летальным исходом, огнестрельное оружие использовалось в $60 \%$ случаев, а после их убийства нападающий (пациент) совершал самоубийство в $50 \%$, обычно аналогичным с убийством способом. Это существенным образом отличается от других (обычных) убийств в России, которые чаще всего совершаются колото-режущими и тупыми предметами, а самоубийства после убийств обычно не встречаются [41].
Довольно интересными выглядят данные S. Flynn с соавт. [23], которые разделили самоубийства по времени совершения на «немедленные» (до 3 дней после убийства) и «отложенные» (позже 3 дней, но до вынесения приговора). Лица с отложенными самоубийствами имели меньший средний возраст (37 vs 43 лет), чаще совершали внесемейные ПГСУ (убивали знакомых и чужих людей), самоубийства совершали путём повешения. Те, кто совершал самоубийства в течение трех дней и ближайших часов после убийства, убивали своих супругов / партнеров и уходили из жизни с помощью огнестрельного оружия [23].

ПГСУ в 70,1-82,3\% случаев совершаются в помещениях частных домов (апартаментов), квартирах жертв и преступников $[13,24]$. Чаще всего это были спальня (22-39\%), зал (19\%), кухня (27\%), гараж (22\%) [29]. Убийства и самоубийства, совершённые в спальне - свидетельство близких отношений между преступником и его жертвой $[22,35]$. На улице совершалось 23,6-24,8\% ПГСУ [14], трассе (9,7\%), территории кафе и ресторанов (7,0\%) [39], публичных местах [29]. Для сравнения обычные убийства совершались в домах в 47-66\% случаев, а обычные самоубийства - в $51-57 \%$ [32]. 
ПГСУ и обычные убийства и самоубийства. Уникальность ПГСУ проявляется при сравнении $[18,40]$. Так, оно отличается от обычных убийств тем, что чаще используется огнестрельное оружие, жертвами становятся дети, супруг(а) агрессора, включая бывших партнеров, преступники и жертвы реже находились в состоянии алкогольного либо другого опьянения [23]. В дополнение к сказанному, можно ещё добавить из цитируемого исследования более старший возраст лиц, совершивших ПГСУ, по сравнению с обычными убийцами (41 vs 28 лет), частое удушение жертв (21 vs 7\%), наличие двух и более погибших (19 vs 3\%), тревожные, панические, обсессивнокомпульсивные расстройства (15 vs 4\%); при обычных убийствах жертвами чаще становятся знакомые люди, но не члены семьи и партнеры (38 vs $8 \%$ ) и незнакомые люди (22 vs $2 \%$ ). В Швейцарии наличие алкогольного опьянения, домашнее насилие в анамнезе, безработица наблюдались реже при ПГСУ, чем при обычных убийствах [21], а в США напротив опьянение ПАВ чаще приводило к ПГСУ [34].

Лица, совершившие обычные самоубийства, отличались от случаев ПГСУ более частым обращением к специалистам психиатрической службы, наличием тяжелых (хронических) ПР (шизофрения или аффективные расстройства), уходом из жизни путём самоотравления. При ПГСУ для самоубийства преступники прибегали к огнестрельному оружию, чаще страдали личностными расстройствами [16]. Риск суицида возрастает после убийства детей, интимного партнера (настоящего или прошлого), если преступление совершалось с помощью огнестрельного оружия и путём удушения, лицом 55 лет и старше [24]. Не влияло на суицидальное поведение преступника убийство знакомых или незнакомых лиц, представителей этнических меньшинств [16].

В Австралии рассчитана вероятность совершения самоубийства преступником с ПГСУ: если жертва - дети, то риск возрастает в 9,7 раза; бывший супруг(a) - в 4,6; настоящий супруг / партнер - в 3,2; используется огнестрельное оружие - в 5,2 раза. Авторы уточняют, что вероятность самоубийства увеличивается, если преступник старше жертвы (в 3,7 раза), он мужчина, а жертва женщина (в 3,7$)$, преступники и жертва белой расы (в 4,8), а факт наличия алкогольного опьянения практически никак не провоцирует самоубийство (в 0,3 раза) [24]. Риск совершения самоубийства минимален при убийстве знакомых и незнакомых людей, представителей национальных меньшинств, если возраст преступника меньше 55 лет [23]. Схожие закономерности получены в США [28].

ПГСУ в СМИ, интернете. Отмечается неточность и избирательность информации, собранной о ПГСУ, в прессе и интернете. В частности, P. Roma с соавт. [42] отмечают, что материал во многом зависит от редакторской политики издания, с ориентацией на сенсационность и медийный интерес. Например, ПГСУ с гибелью детей привлекает внимание читателей больше, нежели с участием пожилой семейной пары [39]. Причины ПГСУ нередко искажаются, описываются спекулятивно и предвзято, гипертрофируя личность убийцы, способы и методы агрессии, факт самоубийства при этом особо не акцентируется, являясь мелким штрихом к очерченному событию, что может быть следствием ограничений для СМИ на освещение тематики суицида согласно национальным кодам журналистики, Советам по прессе, рекомендациям экспертов Всемирной организации здравоохранения. Несмотря на указанные недостатки, изучение ПГСУ в СМИ с помощью контент-анализа является одним из возможных способов исследования, сбора недостающей информации о деликте [42].

Рассчитанные показатели ПГСУ в СМИ зачастую соответствуют данным научной литературы, что, возможно, объясняется репрезентативностью собранной информации (662 ПГСУ в течение 1985-2008 гг., совершённых в Италии) [42]. Более того, достоверность многих выводов удалось подтвердить судебномедицинским исследованием ПГСУ (аутопсией), совершённых в провинции Милан (более 3 млн жителей, проживающих в 134 муниципалитетах) в 1990-2009 гг. [22]. Авторы, между тем, отметили трудности при сборе сведений о причинах ПГСУ, особенно при уточнении ПР у преступников и их жертв.

Сведения о ПГСУ в Китае в 2000-2014 гг., также пока во многом основываются на данных, взятых из газетных репортажей центральных изданий страны. Оказалось, что многие паттерны ПГСУ там соответствуют таковым в высокоразвитых странах мира [27]. Исключениями являются способы убийства (холодное оружие $-66 \%$, отравления $-27 \%$ ) и самоубийства (падение с высоты - 48,3\%; отравления $21,7 \%)$, лидерство внесемейных ПГСУ (42\%) и убийств членов семьи (39\%), против партнеров / супругов (14\%), отсутствие ПГСУ из жалости (“mercy killing") [17]. При этом прослеживались две крайние точки зрения на ПГСУ в 
СМИ Китая: либо это ПР (критерий необоснованной жестокости), либо «дьявольская сила». Авторы откровенно пишут об ограничениях своего исследования, указывая малочисленность наблюдений (63 ПГСУ) и неполноту сведений [27]. Исследование ПГСУ, проведённое в Гонконге (Китай) в 1989-1998 гг., подтвердили известные социально-демографические показатели (пол, возраст преступников и их жертв), редкость использования огнестрельного оружия, отсутствие ПГСУ из-за жалости, взятые из прессы. Однако по орудиям убийств и самоубийств, социальным показателям эта выборка отличалась от описанной в газетных репортажах [17].

Другой мотивацией изучения ПГСУ в СМИ является составление портрета этого противоправного акта, особенно описание ПР в прессе. В Англии и Уэльсе удалось найти сведения о 90\% ПГСУ (54 из 60), совершённых за три года (2006-2008). Основные акценты в статьях делались на экстремальность агрессии и личной трагедии, убийству уделялось основное место в репортаже с типичными журналистскими стереотипами о личности убийцы, зачастую психически больном человеке и спекуляции о ПР как основной причине трагедии. Определённые сочувственные нотки можно было встретить в статьях о ПГСУ из-за жалости (альтруистические мотивы) и резко интолерантные высказывания про людей с ПР («чокнутый, убивающий не первый раз», «сумасшедший отец, который задушил свою жену и четверых детей, после чего повесился сам»). Несмотря на использование стигматизирующих выражений, в ряде статей отмечалось уменьшение негативных и резких высказываний, касающихся психически больных, включая преступников (убийц), совершивших агрессивные деликты [36].

Данные о ПГСУ могут не раскрываться в СМИ по религиозным мотивам, соображениям стигмы родственников погибших, профессиональной журналистской этике, из-за «тайны следствия» и другим причинам.

Профилактика ПГСУ. Представляет весьма трудную задачу в связи с тем, что преступники и жертвы ПГСУ отличаются от обычных убийц и суицидентов $[18,21,23,40]$. Это, как правило, лица среднего класса с высшим образованием, семейные люди с детьми, не имеющие судимости, зрелого возраста [13, 26], реже, чем обычные граждане, замеченные в домашнем насилии, не злоупотребляющие ПАВ (алкоголем) [21]. Определённо, есть своя специфика, характерная для той или иной страны. Например, в Гонконге (Китай) ПГСУ чаще совершали безработные граждане $(61,7 \%)$, имеющие низкую профессиональную квалификацию и низкий образовательный уровень $(76,7 \%$ - окончили 9 классов и ниже), социально-экономические проблемы $(38,3 \%)$. Отсутствие доступа к огнестрельному оружию не помешало им совершить ПГСУ; ПР были выявлены примерно у 30\% (депрессивные состояния, психозы). Катализатором преступления явились прекращения сексуальных (семейных) отношений $(29,3 \%)$, финансовые причины $(25,0 \%)$ и домашнее неблагополучие $(19,6 \%)$ [17]. В Швейцарии к факторам, способствующим ПГСУ, относили: свободное хождение огнестрельного оружия, развод с супругой (расставание с любимым человеком), отсутствие гражданства страны проживания, религиозная неопределённость и проживание в переполненных жилищах (хозяйствах), а другие показатели не играли существенной роли [25].

Приведённые примеры убеждают в исследовании ПГСУ в каждой стране (регионе) миpa, чтобы определить свои специфические факторы совершения ПГСУ $[2,3,5]$. Можно согласиться с общими рекомендациями по ограничению огнестрельного оружия у населения, контроль за его выдачей психически нездоровым лицам, борьба с преступностью, направленная на сокращение и предупреждение криминальной агрессии (преступлений против здоровья и жизни граждан), включая различные проявления домашнего насилия [4]. Предупреждению ПГСУ может помочь своевременное выявление ПР с суицидальной направленностью (депрессивные состояния, ПР, обусловленные приёмом ПАВ), в первую очередь врачами общей практики (семейными) [43]. К примеру, снижение случаев ПГСУ на протяжении 20 лет в Швеции и США связывают с эффективным лечением депрессий [15]. Качественное оказание психиатрической и геронтологической помощи гражданам, разработка реабилитационных мероприятий другим категориям больных с хроническими заболеваниями (сердечно-сосудистыми, неврологическими, онкологическими и др.), психологосоциальная помощь лицам, оказавшимся в трудной жизненной ситуации (пожилым, многодетным, одиноким и др.), определённо, могут внести свой вклад в сокращение случаев ПГСУ $[35,39]$. Такой комплекс превентивных мер можно встретить в зарубежных научных статьях, посвященных ПГСУ. 


\section{Заключение.}

Таким образом, ПГСУ является самостоятельным и редким видом противоправного поведения, который встречается во многих странах мира $[2,3,5]$. ПГСУ чаще всего касается членов семьи. Этот принцип положен в классификацию самоубийств, совершённых после убийств. Преступниками обычно оказываются мужчины, а жертвами - женщины и дети, первые объективно старше вторых по возрасту [1, $28,34]$. ПГСУ совершается различными орудиями, с преобладанием огнестрельного оружия, в странах, где оно имеется в свободной продаже [6, 32, 37]. ПР (депрессивные состояния) играют заметную роль в совершении ПГСУ $[16,30,33]$. Поэтому профилактика ПГСУ предполагает не только ограничение (запрет) продажи огнестрельного оружия, сокращение числа убийств (различных видов насилия), но и своевременное выявление и лечение психической патологии, включая суицидальное поведение $[4,5,7]$.

В России на сегодняшний день проведены единичные исследования ПГСУ, что связано с трудностями сбора информации, отсутствием стройной и единой системы регистрации таких случаев в правоохранительных органах и су-

Литература:

1. Barraclough B., Harris E.C. Suicide preceded by murder: the epidemiology of homicide-suicide in England and Wales 198892. Psychol. Med. 2002; 32 (4): 577-584.

2. Byard R.W. Murder-Suicide: An Overview. Forensic Pathology Reviews. 2005; 3: 337-347.

3. Eliason S. Murder-suicide: a review of the recent literature. $J$ Am. Acad. Psychiatry Law. 2009; 37 (3): 371-6.

4. Large M., Smith G., Nielssen O. The epidemiology of homicide followed by suicide: a systematic and quantitative review. Suicide Life Threat. Behav. 2009; 39 (3): 294-306. doi:10.1521/suli.2009.39.3.294.

5. Liem M. Homicide followed by suicide: A review. Aggress. Violent Behav. 2010; 15 (3): 153-61. doi: 10.1016/j.avb.2009.10.001

6. Liem M., Oberwittler D. Homicide Followed by Suicide in Europe. Handbook of European Homicide Research: Patterns, Explanations, P. and Country Studies. Springer Science+Business Media, 2012: 197-215. doi: 10.1007/978-1-4614-0466-8_12.

7. Roma P., Pazzelli F., Pompili M., Lester D., Girardi P., Ferracuti S. Mental illness in homicide-suicide: a review. J. Am. Acad. Psychiatry Law. 2012; 40 (4): 462-8.

8. Голенков А.В. Постгомицидные самоубийства: описание 5 случаев. Российский психиатрический журнал. 2017; 2: 12-6.

9. Голенков А.В. Распространенность и особенности постгомицидных суицидов на примере одного из регионов России. Психическое здоровье. 2018; 16 (2): 9-13. doi: 10.25557/2074014X.2018.02.9-13.

10. Горинов В.В. Посмертная судебно-психиатрическая экспертиза в уголовном процессе / Руководство по судебной психиатрии // Под ред. А.А. Ткаченко. 2-е изд., перераб. и дополн. М.: Юрайт, 2015. Гл. 6. С. 200-209.

11. Golenkov A., Large M., Nielssen O., Tsymbalova A. Homicide and mental disorder in a region with a high homicide rate. Asian $\begin{array}{llll}\text { J. } & \text { Psychiatry. } & 2016 ; & 23:\end{array}$ doi.org/10.1016/j.ajp.2016.07.015. дебно-медицинских экспертных организациях. Лишь небольшая часть освещается в СМИ и интернете [8, 9, 41]. Эти сообщения, как правило, кратки и весьма произвольно отражают фабулу инцидента. Зачастую отсутствуют указания на время самоубийства после убийства, что имеет порой важное значение для включения / исключения случаев в статистику ПГСУ, не приводятся мотивы, возраст и пол участников (жертв) и их семейные (родственные) взаимосвязи, оружие убийства / самоубийства, психическое состояние каждого фигуранта дела. Всё вышеуказанное затрудняет исследование ПГСУ, изучение эпидемиологических, судебно-психиатрических (медицинских), социально-психологических и криминологических аспектов. Отсутствие стандартизированных репрезентативных и полных сведений о ПГСУ затрудняют сопоставление с другими схожими исследованиями на внутрирегиональном (межтерриториальном) и международном уровне. Пока редкое направление ПГСУ на судебно-психиатрическую экспертизу в нашей стране не позволяет в полной мере оценить роль ПР в совершении этого противоправного деяния с несколькими жертвами, а значит разрабатывать меры его профилактики.

\section{References:}

1. Barraclough B., Harris E.C. Suicide preceded by murder: the epidemiology of homicide-suicide in England and Wales 1988-92. Psychol. Med. 2002; 32 (4): 577-584.

2. Byard R.W. Murder-Suicide: An Overview. Forensic Pathology Reviews. 2005; 3: 337-347.

3. Eliason S. Murder-suicide: a review of the recent literature. $J$. Am. Acad. Psychiatry Law. 2009; 37 (3): 371-6.

4. Large M., Smith G., Nielssen O. The epidemiology of homicide followed by suicide: a systematic and quantitative review. Suicide Life Threat. Behav. 2009; 39 (3): 294-306. doi:10.1521/suli.2009.39.3.294.

5. Liem M. Homicide followed by suicide: A review. Aggress. Vio$\begin{array}{lllll}\text { lent Behav. 2010; } 15 & \text { (3): 153-61. doi: }\end{array}$ 10.1016/j.avb.2009.10.001

6. Liem M., Oberwittler D. Homicide Followed by Suicide in Europe. Handbook of European Homicide Research: Patterns, Explanations, P. and Country Studies. Springer Science+Business Media, 2012: 197-215. doi: 10.1007/978-1-4614-0466-8_12.

7. Roma P., Pazzelli F., Pompili M., Lester D., Girardi P., Ferracuti S. Mental illness in homicide-suicide: a review. J. Am. Acad. Psychiatry Law. 2012; 40 (4): 462-8.

8. Golenkov A.V. Postgomicide suicide: a description of 5 cases. Russian Psychiatric Journal. 2017; 2: 12-6. (In Russ)

9. Golenkov A.V. Prevalence and peculiarities of post-homicide suicides on the example of one of the regions of Russia. Mental health. 2018; 16 (2): 9-13. doi: 10.25557 / 2074014X.2018.02.9-13. (In Russ)

10. Gorinov V.V. Posthumous forensic psychiatric examination in the criminal process / Manual of Forensic Psychiatry // Ed. A.A. Tkachenko. $2^{\text {nd }}$ ed., Revised. and add. M.: Yurayt, 2015. Ch. 6. P. 200-209. (In Russ)

11. Golenkov A., Large M., Nielssen O., Tsymbalova A. Homicide and mental disorder in a region with a high homicide rate. Asian $\begin{array}{llll}\text { J. } & \text { Psychiatry. 2016; 87-92. }\end{array}$ doi.org/10.1016/j.ajp.2016.07.015. 
12. Ардашев Р.Г., Китаева В.Н. Судебные психиатрические и психолого-психиатрические экспертизы при расследовании убийств, осложненных суицидом правонарушителей. Закон $u$ право. 2013; 8: 86-87.

13. Bossarte R.M., Simon T.R., Barker L. Characteristics of homicide followed by suicide incidents in multiple states, 2003-04. Inj. Prev. 2006; 12 (2): 33-38. doi: 10.1136/ip.2006.012807.

14. Logan J., Hill H.A., Black M.L., Crosby A.E., Karch D.L., Barnes J.D., Lubell K.M. Characteristics of perpetrators in homicide-followed-by-suicide incidents: National Violent Death Reporting System - 17 US States, 2003-2005. Am. J. Epidemiol. 2008; 168 (9): 1056-1064. doi: 10.1093/aje/kwn213.

15. Regoeczi W.C., Granath S., Issa R., Gilson T., Stump J. Comparing Homicide-Suicides in the United States and Sweden. J. Fo rensic Sci. - 2016; 61 (6): 1524-1530. doi: 10.1111/15564029.13194.

16. Flynn S., Gask L., Appleby L., Shaw J. Homicide-suicide and the role of mental disorder: a national consecutive case series. Soc Psychiatry Psychiatr. Epidemiol. 2016; 51 (6): 877-884. doi: 10.1007/s00127-016-1209-4.

17. Chan C.Y., Beh S.L., Broadburst R.G. Homicide-suicide in Hong Kong, 1989-1998. Forensic. Sci. Int. 2004; 140 (2-3): 261-267.

18. Liem M., Hengeveld M., Koenraadt F. Domestic homicide followed by parasuicide: a comparison with homicide and parasuicide. Int. J. Offender Ther. Comp. Criminol. 2009; 53 (5): $497-$ 516. doi: 10.1177/0306624X09334646.

19. Marzuk P.M., Tardiff K., Hirsch C.S. The epidemiology of murder-suicide. AMA. 1992; 267 (23): 3179-3183.

20. Roberts K., Wassenaar D., Canetto S.S., Pillay A. Homicidesuicide in Durban, South Africa. J. Interpers Violence. 2010; 25 (5): 877-899. doi: 10.1177/0886260509336964

21. Panczak R., Geissbilhler M., Zwahlen M., Killias M., Tal K. Egger M. Homicide-suicides compared to homicides and suicides: systematic review and meta-analysis. Forensic Sci. Int 2013; 233 (1-3): 28-36. doi: 10.1016/j.forsciint.2013.08.017.

22. Merzagora I., Travaini G., Battistini A., Pleuteri L. Murdersuicide in the province of Milan, Italy: criminological analysis of cases 1990-2009. Med. Sci. Law. 2011; 51 (2): 87-92. doi: 10.1258/msl.2010.010086.

23. Flynn S., Swinson N., While D., Hunt I.M., Roscoe A., Rodway C., Kapur N., Appleby L., Shaw J. Homicide followed by suicide: a cross-sectional study. J. Forensic Psychiatry \& Psychology. 2009; 20 (2): 306-321. doi: 10.1080/14789940802364369.

24. Carcach C., Grabosky P.N. Murder-suicide in Australia Australian Institute of Criminology Trends and Issues in Crime and Criminal Justice. Canberra. 1998; March (82): 6.

25. Panczak R., Zwahlen M., Spoerri A., Tal K., Killias M., Egger M Incidence and risk factors of homicide-suicide in Swiss households: National Cohort study. PLoS One. 2013; 8 (1): 53714. doi.org/10.1371/journal.pone.0053714

26. McPhedran S., Eriksson L., Mazerolle P., De Leo D., Johnson H., Wortley R. Characteristics of Homicide-Suicide in Australia: A Comparison With Homicide-Only and Suicide-Only Cases. J. Interpers Violence. 2018; 33 (11): 1805-1829. doi: $10.1177 / 0886260515619172$

27. Densley J., Hilal S.M., Li S.D., Tang W. Homicide-Suicide in China: an Exploratory Study of Characteristics and Types Asian J. Criminology. 2017; 12 (3): 199-216. doi: 10.1007/s11417016-9238-1.

28. Stack S. Homicide followed by suicide: An analysis of Chicago data. Criminology. 1997; 35 (3): 435-453.

29. De Koning E., Piette M.H. A retrospective study of murdersuicide at the Forensic Institute of Ghent University, Belgium: 1935-2010. Med. Sci. Law. 2014; 54 (2): 88-98. doi: $10.1177 / 0025802413518018$

30. Kotzé C., Khamker N., Lippi G., Naidu K., Pooe J.M., Funeka B., Sokudela F.B., Roos L. Psychiatric and Other Contributing Factors in Homicide-Suicide Cases, from Northern Gauteng, South Africa Over a Six-Year Period. Int. J. Forensic Mental Health. 2018; 17 (1): 35-44. doi.org/10.1080/14999013.2017.1416004.

31. Dogan K.H., Demirci S., Gunaydin G., Buken B. Homicidesuicide in Konya, Turkey between 2000 and 2007. J. Forensic Sci. 2010; 55 (1): 110-115. doi: 10.1111/j.15564029.2009.01239.x.

32. Liem M., Barber C., Markwalder N., Killias M., Nieuwbeerta P. Homicide-suicide and other violent deaths: an international comparison. Forensic Sci. Int. 2011; 207 (1-3): 70-76. doi: $10.1080 / 14789940802364369$.
12. Ardashev R.G., Kitaeva V.N. Forensic psychiatric and psychopsychiatric examinations in the investigation of murders complicated by suicide of offenders. Law and Law. 2013; 8: 86-87. (In Russ)

13. Bossarte R.M., Simon T.R., Barker L. Characteristics of homicide followed by suicide incidents in multiple states, 2003-04. Inj. Prev. 2006; 12 (2): 33-38. doi: 10.1136/ip.2006.012807.

14. Logan J., Hill H.A., Black M.L., Crosby A.E., Karch D.L., Barnes J.D., Lubell K.M. Characteristics of perpetrators in homicide-followed-by-suicide incidents: National Violent Death Reporting System - 17 US States, 2003-2005. Am. J. Epidemiol. 2008; 168 (9): 1056-1064. doi: 10.1093/aje/kwn213.

15. Regoeczi W.C., Granath S., Issa R., Gilson T., Stump J. Comparing Homicide-Suicides in the United States and Sweden. J. Forensic Sci. - 2016; 61 (6): 1524-1530. doi: 10.1111/15564029.13194

16. Flynn S., Gask L., Appleby L., Shaw J. Homicide-suicide and the role of mental disorder: a national consecutive case series. Soc Psychiatry Psychiatr. Epidemiol. 2016; 51 (6): 877-884. doi: 10.1007/s00127-016-1209-4.

17. Chan C.Y., Beh S.L., Broadburst R.G. Homicide-suicide in Hong Kong, 1989-1998. Forensic. Sci. Int. 2004; 140 (2-3): 261-267.

18. Liem M., Hengeveld M., Koenraadt F. Domestic homicide followed by parasuicide: a comparison with homicide and parasuicide. Int. J. Offender Ther. Comp. Criminol. 2009; 53 (5): $497-$ 516. doi: 10.1177/0306624X09334646.

19. Marzuk P.M., Tardiff K., Hirsch C.S. The epidemiology of murder-suicide. AMA. 1992; 267 (23): 3179-3183.

20. Roberts K., Wassenaar D., Canetto S.S., Pillay A. Homicidesuicide in Durban, South Africa. J. Interpers Violence. 2010; 25 (5): 877-899. doi: 10.1177/0886260509336964

21. Panczak R., Geissbilhler M., Zwahlen M., Killias M., Tal K., Egger M. Homicide-suicides compared to homicides and suicides: systematic review and meta-analysis. Forensic Sci. Int. 2013; 233 (1-3): 28-36. doi: 10.1016/j.forsciint.2013.08.017.

22. Merzagora I., Travaini G., Battistini A., Pleuteri L. Murdersuicide in the province of Milan, Italy: criminological analysis of cases 1990-2009. Med. Sci. Law. 2011; 51 (2): 87-92. doi: 10.1258/ms1.2010.010086.

23. Flynn S., Swinson N., While D., Hunt I.M., Roscoe A., Rodway C., Kapur N., Appleby L., Shaw J. Homicide followed by suicide: a cross-sectional study. J. Forensic Psychiatry \& Psychology. 2009; 20 (2): 306-321. doi: 10.1080/14789940802364369.

24. Carcach C., Grabosky P.N. Murder-suicide in Australia Australian Institute of Criminology Trends and Issues in Crime and Criminal Justice. Canberra. 1998; March (82): 6.

25. Panczak R., Zwahlen M., Spoerri A., Tal K., Killias M., Egger M. Incidence and risk factors of homicide-suicide in Swiss households: National Cohort study. PLoS One. 2013; 8 (1): 53714. doi.org/10.1371/journal.pone.0053714.

26. McPhedran S., Eriksson L., Mazerolle P., De Leo D., Johnson H., Wortley R. Characteristics of Homicide-Suicide in Australia: A Comparison With Homicide-Only and Suicide-Only Cases. J. Interpers Violence. 2018; 33 (11): 1805-1829. doi $10.1177 / 0886260515619172$

27. Densley J., Hilal S.M., Li S.D., Tang W. Homicide-Suicide in China: an Exploratory Study of Characteristics and Types Asian. J. Criminology. 2017; 12 (3): 199-216. doi: 10.1007/s11417016-9238-1.

28. Stack S. Homicide followed by suicide: An analysis of Chicago data. Criminology. 1997; 35 (3): 435-453.

29. De Koning E., Piette M.H. A retrospective study of murdersuicide at the Forensic Institute of Ghent University, Belgium: 1935-2010. Med. Sci. Law. 2014; 54 (2): 88-98. doi: $10.1177 / 0025802413518018$

30. Kotzé C., Khamker N., Lippi G., Naidu K., Pooe J.M., Funeka B., Sokudela F.B., Roos L. Psychiatric and Other Contributing Factors in Homicide-Suicide Cases, from Northern Gauteng, South Africa Over a Six-Year Period. Int. J. Forensic Mental Health 2018; 17 (1): 35-44. doi.org/10.1080/14999013.2017.1416004.

31. Dogan K.H., Demirci S., Gunaydin G., Buken B. Homicidesuicide in Konya, Turkey between 2000 and 2007. J. Forensic Sci. 2010; 55 (1): 110-115. doi: 10.1111/j.15564029.2009.01239.x

32. Liem M., Barber C., Markwalder N., Killias M., Nieuwbeerta P. Homicide-suicide and other violent deaths: an international comparison. Forensic Sci. Int. 2011; 207 (1-3): 70-76. doi: $10.1080 / 14789940802364369$. 
33. Coid J. The epidemiology of abnormal homicide and murder followed by suicide. Psychol. Med. 1983; 13 (4): 855-860.

34. Regoeczi W.C., Gilson T. Homicide-Suicide in Cuyahoga County, Ohio, 1991-2016. J. Forensic Sci. 2018; 8. doi: 10.1111/1556-4029.

35. Salari S. Patterns of intimate partner homicide suicide in later life: strategies for prevention. Clin. Interv Aging. 2007; 2 (3): 441-452.

36. Flynn S., Gask L., Shaw J. Newspaper reporting of homicidesuicide and mental illness. B.J. Psych. Bull. 2015; 39 (6): 268-72. doi: 10.1192/pb.bp.114.049676.

37. Lecomte D., Fornes P. Homicide followed by suicide: Paris and its suburbs, 1991-1996. J. Forensic. Sci. 1998; 43 (4): 760-764.

38. Satoh F., Osawa M. Trend of homicide-suicide in Kanagawa Prefecture (Japan): Comparison with western countries. Med. Sci. Law. 2016; Oct. 3. pii: 0025802416668769. - doi: $10.1177 / 0025802416668769$.

39. Cohen D., Llorente M., Eisdorfer C. Homicide-suicide in older persons. Am. J. Psychiatry. 1998; 155 (3): 390-396. doi:10.1176/ajp.155.3.390.

40. Liem M., Nieuwbeerta P. Homicide followed by suicide: a comparison with homicide and suicide. Suicide Life Threat Behav. 2010; 40 (2): 133-145. doi:10.1521/suli.2010.40.2.133.

41. Голенков А.В. Гибель медицинских работников от рук больных (психиатрический аспект). Медииинская сестра. 2018; 20 (1): 20-23. doi: 10.29296/25879979-2018-01-06.

42. Roma P., Spacca A., Pompili M., Lester D., Tatarelli R., Girardi P., Ferracuti S. The epidemiology of homicide-suicide in Italy: a newspaper study from 1985 to 2008. Forensic Sci. Int. 2012; 10, 214 (1-3). e1-5. doi: 10.1016/j.forsciint.2011.06.022.

43. Bell C.C., McBride D.F. Commentary: Homicide-suicide in older adults - cultural and contextual perspectives. J. Am. Acad. Psychiatry Law. - 2010; 38 (3): 312-317.
33. Coid J. The epidemiology of abnormal homicide and murder followed by suicide. Psychol. Med. 1983; 13 (4): 855-860.

34. Regoeczi W.C., Gilson T. Homicide-Suicide in Cuyahoga County, Ohio, 1991-2016. J. Forensic Sci. 2018; 8. doi: 10.1111/1556-4029.

35. Salari S. Patterns of intimate partner homicide suicide in later life: strategies for prevention. Clin. Interv Aging. 2007; 2 (3): 441-452.

36. Flynn S., Gask L., Shaw J. Newspaper reporting of homicidesuicide and mental illness. B.J. Psych. Bull. 2015; 39 (6): 268-72. doi: 10.1192/pb.bp.114.049676.

37. Lecomte D., Fornes P. Homicide followed by suicide: Paris and its suburbs, 1991-1996. J. Forensic. Sci. 1998; 43 (4): 760-764.

38. Satoh F., Osawa M. Trend of homicide-suicide in Kanagawa Prefecture (Japan): Comparison with western countries. Med. Sci. Law. 2016; Oct. 3. pii: 0025802416668769. - doi: $10.1177 / 0025802416668769$.

39. Cohen D., Llorente M., Eisdorfer C. Homicide-suicide in older persons. Am. J. Psychiatry. 1998; 155 (3): 390-396. doi:10.1176/ajp.155.3.390.

40. Liem M., Nieuwbeerta P. Homicide followed by suicide: a comparison with homicide and suicide. Suicide Life Threat Behav. 2010; 40 (2): 133-145. doi:10.1521/suli.2010.40.2.133.

41. 41. Golenkov A.V. The death of medical workers at the hands of patients (psychiatric aspect). Medical sister. 2018; 20 (1): 20-23. doi: 10.29296 / 25879979-2018-01-06. (In Russ)

42. Roma P., Spacca A., Pompili M., Lester D., Tatarelli R., Girard P., Ferracuti S. The epidemiology of homicide-suicide in Italy: a newspaper study from 1985 to 2008. Forensic Sci. Int. 2012; 10, 214 (1-3). e1-5. doi: 10.1016/j.forsciint.2011.06.022.

43. Bell C.C., McBride D.F. Commentary: Homicide-suicide in older adults - cultural and contextual perspectives. J. Am. Acad. Psychiatry Law. - 2010; 38 (3): 312-317.

\section{POST-HOMICIDE SUICIDES: REVIEW OF LITERATURE}

\section{A.V. Golenkov}

I.N. Ulyanov Chuvash State University, Cheboksary, Russia, golenkovav@inbox.ru

\section{Abstract:}

Suicide committed after the homicide, is a brutal form of aggressive behavior that is rarely observed in everyday life. In our opinion, in Russian, the term "post-homicide suicides" (PHS) is concise and inclusive. The present review of the literature is aimed at examining the main results of foreign research on PHS. Criteria for typology of PHS has been fluctuating over a wide time frame (hours and months), there is also a reasonable proposal to take into account the causal relationship between homicide and subsequent suicide. Spousal (intimate partner) PHS are the most common (40-70\% of all cases), filicide-suicide (2.9-36\%), familicide-suicide (2-31.9\%) and extra-familial (2.9-40\%) PHS. Prevalence of PHS in different countries of the world ranges from 0.4 to 8.9 cases per 1 million inhabitants. In Chuvashia (a region of Russia), the cases of PHS range from 1 to 6 (on average $-4.2 \pm 2.0$ cases per year) or from 0,8 to 4,84 (on average - 3.33 cases) per 1 million inhabitants. Most research results would include the following as motives of the PHS - pathological jealousy (amorous jealousy), stress, "mercy killing" or altruistic were discussed; often (in $25-50 \%$ ) it is not possible to identify motives. Mental disorders (MD) are seen as an important cause of PHS, ranging from 3 to $100 \%$. Depressive states were markedly leading (from 8.6 to $87 \%$ ), as well as many comorbid conditions, $\mathrm{MD}$, caused by the intake of psychoactive substances and various forms of suicidal behavior (thoughts, attempts, selfharm) - in the anamnesis (from 2.6 to $51 \%$ ). PHS was significantly more often performed by males $(75-91.4 \%$ of cases). Victims, on the contrary, were more often females and children (50-83\%). The age of the offenders was regularly older than the age of the victims. The weapon of homicides and suicides in most countries was firearms. It is acceptable to study PHS in the mass media. Prevention of PHS is a very difficult task due to the fact that criminals and victims of PHS are different from homicide-only and suicide-only cases. These aspects persuade the study of PHS in each country (region) of the world in order to determine its specific factors in the execution of PHS and develop measures for its prevention.

Keywords: post-homicide suicides (suicides committed after the homicide), mental disorders, epidemiology, factors, prevention

Финансирование: Исследование не имело спонсорской поддержки.

Конфмикт интересов: Автор заявцяет об отсутствии конфмикта интересов.

Для цитирования: Голенков А.В. Постгомицидные самоубийства. Суицидология. 2018; 9 (3): 3 -15. doi: https://doi.org/10.32878/suiciderus.18-09-03(32)-3-15

For citation: $\quad$ Golenkov A.V. Post-homicide suicides: review of literature. Suicidology. 2018; 9 (3): 3-15. (In Russ) doi: https://doi.org/10.32878/suiciderus.18-09-03(32)-3-15 